\title{
LACASSE CATALYZED-SYNTHESIS OF 4,4'-BIPHENYLDIAMINE FROM P-CHLOROANILINE. EVALUATION OF ANTIFUNGAL AND ANTIOXIDANT ACTIVITIES
}

\author{
ANA M. CAMPOS ${ }^{1}$, LEONORA MENDOZA $^{* 1}$, JUAN VASQUEZ ${ }^{1}$, RICARDO MELO ${ }^{\prime}$, \\ JENNIFER SALAS ${ }^{\prime}$ MILENA COTORAS ${ }^{1 *}$
}

${ }^{1}$ Facultad de Química y Biología, Universidad de Santiago de Chile. Casilla 40-Correo 33, Santiago-Chile

\begin{abstract}
Laccase is a copper-containing oxidase that catalyzes reduction of molecular oxygen to water and the oxidation of a phenolic compound. In this paper, laccase was utilized to synthesize 4,4'-Biphenyldiamine using $p$-chloroaniline as substrate by means of a coupling reaction. The synthesized compound, 4,4'-Biphenyldiamine, presented low antifungal activity against the phytopathogenic fungus Botrytis cinerea, however the antioxidant ability, measurement by ORAC-PGR method, was higher than substrate.

This work corresponds to the first report of synthesis 4,4'-Biphenyldiamine, from $p$-chloroaniline in a lacasse-catalyzed reaction.
\end{abstract}

Keywords: $p$-chloroaniline, 4,4'-Biphenyldiamine, laccase, antioxidant activity, antifungal activity.

\section{INTRODUCTION}

Laccases (benzenediol: oxygen oxidoreductase, EC 1.10.3.2) are coppercontaining oxidases that catalyze the single-electron oxidation of a wide range of phenolic compounds and reduction of molecular oxygen to water ${ }^{1}$. The produced radical can reacts non-enzymatic to produce covalent coupling to form dimers, oligomers and polymers through $\mathrm{C}-\mathrm{C}, \mathrm{C}-\mathrm{O}$ and $\mathrm{C}-\mathrm{N}$ bonds ${ }^{2}$. This enzyme has been used to synthesize hydroxybiphenyl dimers ${ }^{3}$, isoeugenol dimers ${ }^{4}$ and ferulic acid dimers ${ }^{5}$.

Laccase is also able to couple a laccase substrate with a non-laccase substrate (known as a mediator) to form new molecules (heterodimers) ${ }^{2,6}$. Niedermeyer et al. reported the heterodimeric synthesis between $p$-hydroquinones and primary aromatic amines using laccase ${ }^{7}$. Another example is the coupling between $p$-hydroquinones with $p$-aminobenzoic acid ${ }^{8}$. Antibiotic modifications using laccase coupling reactions have shown products with lower activities'; however, using nitrogen compounds to modify the antibiotics, the synthesized products showed higher antibacterial activities ${ }^{10,11}$. The anticancer activity of naphtohydroquinones has been improved by nuclear monoamination with anilines using laccase ${ }^{12}$. These results indicate that the laccase-mediated amination of a phenolic compound could increase their biological activity.

On the other hand, these enzymes utilize as substrates anilines, hydroxyindoles, and benzenethiols and also some inorganic ions such as $\left[\mathrm{Mo}(\mathrm{CN})_{8}\right]^{4},\left[\mathrm{Fe}(\mathrm{CN})_{6}\right]^{4-},\left[\mathrm{Os}(\mathrm{CN})_{6}\right]^{4}$, and $\left.\left[\mathrm{W}(\mathrm{CN})_{8}\right]^{4}\right]^{13}$. It has been reported that laccase catalyses the in vitro polymerization of aniline. However, the polymerization rate is relatively low, therefore mediators must be used ${ }^{14}$.

Likewise, this enzyme has been used to increase the antioxidant activity of several flavonoids by polymerization ${ }^{15}$. On the other hand, laccase has been used to couple antioxidant compounds to wood ${ }^{16}$. Also, due to their demethylation and dehalogenation ability it can be applied to control environmental pollution, for example, as a remediation of soil contaminated with chlorophenol residues ${ }^{17}$ or TNT $(2,4,6 \text {-trinitrotoluene })^{18}$. Furthermore, laccase has been used as stabilizing wine by removing unwanted wine phenolics ${ }^{19}$ and the stabilization of black fruit juice grape is possible by action of this enzyme ${ }^{20}$. Supporting the improve of the antioxidant capacity of certain compound using laccase, it is possible to mention as an example, the functionalization of chitosan by laccasecatalyzed oxidation. Bozic et al. (2013) described that functionalization of chitosan by phenolic acids as a gallic acid and caffeic acid mediated by laccase, enhanced antioxidant and antimicrobial properties ${ }^{21}$. Reinforcing these results, recently Aljawishet al., (2014) reported that the chitosan derivatives presented improved antioxidant properties especially for ferulic acid-chitosan derivative when compared with chitosan alone. In addition, the thermal antioxidant stability as well as the preservation of initial antibacterial activity of chitosan was improved ${ }^{22}$.

Botrytis cinerea, also known as "gray mould fungus", attacks a broad range of host resulting in great economic losses on Chilean export products. However, despite of many varieties of botrycides, the fungus has generated resistance against these chemical products ${ }^{23}$. Therefore, it is imperative to develop new molecules with antifungal activity.

The aim of this work was to analyze the product of laccase-catalyzed reaction utilizing $p$-chloroaniline as substrate and to evaluate the antioxidant and antifungal activity against $B$. cinerea of the obtained product.

\section{EXPERIMENTAL}

\subsection{Chemicals}

Malt extract was obtained from Cramer Co., Ltd. (Santiago, Chile). Yeast extract, Laccase from Trametes versicolor (EC 1.10.3.2), and p-chloroaniline were obtained from Sigma Chemical Co. (St. Louis, MO, USA). Agar was obtained from Difco laboratories (Detroit, MI, USA). Organic solvents and salts were obtained from Merck Química Chilena (Santiago, Chile).

\subsection{Laccase-mediated synthesis of 4,4'-Biphenyldiamine}

A biphasic system containing sodium acetate buffer $(50 \mathrm{mM})$ at $\mathrm{pH}$ of 4.5 and ethyl acetate:acetone (1:0.1) was employed for the laccase reaction. The reaction mixture also contained $p$-chloroaniline $(32.5 \mathrm{mM})$ and laccase (3.79 $\mathrm{U}$ ). The reactions were carried out for $15 \mathrm{~h}$ at $22^{\circ} \mathrm{C}$ with shaking, using an orbital shaker at $200 \mathrm{rpm}$. The reactions were monitored by thin layer chromatography (TLC) on aluminum-backed silica gel 60 F254 (Merck) plates using hexane:ethyl acetate $(7: 3 \mathrm{v} / \mathrm{v})$ as the mobile phase.

After the incubation time, the solvent was evaporated using a rotary evaporator. The product was purified from the reaction mixture using semipreparative thin layer chromatography (TLC silica gel $60 \mathrm{~F}_{254}$ glass plates $20 \times 20 \mathrm{~cm})$ with hexane:ethyl acetate $(8: 2 \mathrm{v} / \mathrm{v})$ as an eluent system. The purity of compound was analyzed by high performance liquid chromatography (HPLC) by using a Waters 600 HPLC chromatograph (Waters, Mildford, MA, USA) equipped with a Waters 2990 diode array detector, and a Symmetry C-18 $(5 \mu \mathrm{m})$ (Waters, Milford, MA, USA) column $(3.9 \mathrm{~mm} \times 150 \mathrm{~mm})$. Chromatography was conducted at $25{ }^{\circ} \mathrm{C}$. Mobile phase was composed of $1.0 \%(\mathrm{v} / \mathrm{v})$ acetic acid in distilled water (A) and acetonitrile (B). The system was run by $60 \mathrm{~min}$ with a gradient program as follows: linear gradient $10-20 \% \mathrm{~B}$ in $20 \mathrm{~min}$ and then $20-50 \%$ B in 25 min was applied. Finally, a gradient $50-100 \%$ B in 15 min was applied. The flow rate was $0.8 \mathrm{~mL} / \mathrm{min}$ and it was recorded at 280 and $360 \mathrm{~nm}$.

The purified product was characterized by nuclear magnetic resonance (NMR) analysis. The ${ }^{1} \mathrm{H}$ NMR $a^{13} d^{13} \mathrm{C}$ NMR spectra were recorded using a Bruker Avance RW- 400 spectrometer operating at $400.13 \mathrm{MHz}$. Measurements were carried out at a probe temperature of $300 \mathrm{~K}$, using deuterated chloroform containing tetramethylsilane (TMS) as an internal standard.

\subsection{Fungal strain and culture conditions}

The strain G29 of B. cinerea was used; it was isolated originally from grapes (Vitis vinifera) by the Instituto de Investigaciones Agropecuarias La Platina, Chile and is genetically characterized ${ }^{24}$. It was maintained on maltyeast extract agar slants with $(2 \%(\mathrm{w} / \mathrm{v})$ malt extract, $0.2 \%(\mathrm{w} / \mathrm{v})$ yeast extract and $1.5 \%(\mathrm{w} / \mathrm{v})$ agar) at $4{ }^{\circ} \mathrm{C}$.

\subsection{Antifungal Assay}

The effect of $p$-chloroaniline and 4,4'-Biphenyldiamine (bencidine) on mycelial growth of $B$. cinerea was assessed in vitro using the radial growth test on malt-yeast extract agar. Different concentrations of the synthesized 
compound and $p$-chloroaniline were dissolved in acetone and added to Petri dishes containing a malt-yeast extract agar medium ( $2 \%$ malt extract, $0.2 \%$ yeast extract and $1 \%$ agar). The final acetone concentration was identical in the control and treatment assays. Commercial fungicide iprodione was used as a control. After evaporation of the acetone in a laminar flow cabinet, the culture medium was inoculated with $0.5 \mathrm{~cm}$ agar disks from an actively growing culture of $B$. cinerea. Cultures were incubated in the dark at $22{ }^{\circ} \mathrm{C}$. Mycelial growth diameters were measured daily. Results were expressed as $\mathrm{IC}_{50}$ (the concentration that reduced mycelial growth by $50 \%$ ), determined by regressing the inhibition of radial growth values (percent control) against the values of compounds concentration.. Each experiment was done at least three times.

2.5 Evaluation of antioxidant activity from compound p-chloronaniline and 4,4'-Biphenyldiamine.

To evaluate the antioxidant activity of the substrate and purified product, the oxygen radical absorbance capacity (ORAC) by the pyrogallol red (PGR) method by used ${ }^{25}$. The oxidation od PGR caused by 2,2'-azobis (2-amidinopropane) dihydrochloride (AAPH), monitored at $540 \mathrm{~nm}$, was evaluated. $5 \mu \mathrm{M}$ PGR and $10 \mathrm{mM}$ AAPH in $75 \mathrm{mM}$ phosphate buffer (pH 7.4) were used as control. The treatments included $30 \mu \mathrm{M} p$-chloronaniline or 30 $\mu \mathrm{M} 4,4^{\prime}$-Biphenyldiamine. The assays were performed at $37^{\circ} \mathrm{C}$. The results were compared with the antioxidant activity of Trolox at $30 \mu \mathrm{M}$.

\section{RESULTS AND DISCUSSION}

\subsection{Synthesis of 4,4'-Biphenyldiamine.}

The lacasse catalyzed-synthesis of 4,4'-Biphenyldiamine (yield 37\%) was carried out using $p$-chloroaniline as substrate. As reaction product a less polar product than the substrate was formed. The coloration of the new compound was a stronger dish brown, while that $p$-chloroaniline was colorless under the used conditions. Based on that, it is possible to conclude that the $p$-chloroaniline was a substrate to laccase. Therefore, at the used reaction conditions, the fungal laccase from $T$. versicolor was able to mediate the cross-coupling of two molecules of $p$-chloroaniline to produce a main product.

After purification by semi-preparative thin layer chromatography, the purity was verified by HPLC retention times by $\mathrm{p}$-chloroaniline and the product were 13.077 and $4.637 \mathrm{~min}$, respectively. The synthesized product was analyzed by ${ }^{1} \mathrm{H}$ NMR and ${ }^{13} \mathrm{C}$ NMR spectroscopy. The signals of this compound were compared with the ${ }^{1} \mathrm{H}$ NMR and ${ }^{13} \mathrm{C}$ NMR spectra of the $p$-chloroaniline (Table $1)$.

In ${ }^{1} \mathrm{H}-\mathrm{NMR}$ spectrum signals corresponding to hydrogen associated to aromatic ring (6.6 and $7.1 \mathrm{ppm}$ ) and hydrogen associated to amine group (3.6 ppmn) were observed. No significant differences were observed between the signals of $p$-chloroaniline and synthesized compound; signals showed the same pattern, but they shifted to lower fields with the exception of corresponding signal to the amine protons (Ha in figure 1). The signal assigned to Hc (Figure 1) showed the clearest difference. This was observed at $7.11 \mathrm{ppm} p$-chloroaniline and in the product at $7.36 \mathrm{ppm}$. In the ${ }^{13} \mathrm{C}$ NMR spectra showed a notable different in the signals assigned to $\mathrm{C}_{4}$ in the $p$-chloroaniline $(123.6 \mathrm{ppm})$ and to $\mathrm{C}_{1}$ and $\mathrm{C}_{1}$ ' in the synthesized product, which shifted to lower field (131.9 ppm). By HSQC and HMBC analyses, it was possible to assign the protons to their respective carbons. Assigning signals, integrations and coupling constants are shown in Table 1, for both compounds, $p$-chloroaniline and synthesized compound.

The shift of the signals of the aromatic protons to a lower field and shift of the $\mathrm{C} 4$ signal of the $p$-chloroaniline suggests that the synthetized compound does not possess chlorine atom, and the structure shown in Figure 1 supports the new signals.

Table 1. ${ }^{1} \mathrm{H}$ NMR and ${ }^{13} \mathrm{C}$ NMR data of $p$-chloroaniline and the synthesized product. In the same row homolog carbons between $p$-chloroaniline and the new synthesized product are shown.

\begin{tabular}{|c|c|c|c|c|c|c|c|c|c|c|c|}
\hline \multicolumn{6}{|c|}{ p-chloroaniline } & \multicolumn{6}{|c|}{ Synthesized product } \\
\hline $\begin{array}{c}\text { Carbon } \\
\text { Atom }\end{array}$ & $\begin{array}{c}\delta_{\mathrm{C}} \\
(\mathrm{ppm})\end{array}$ & Proton & $\begin{array}{c}\delta_{\mathrm{H}} \\
(\mathrm{ppm})\end{array}$ & $\begin{array}{l}\text { Integration } \\
\text { peak }\end{array}$ & $\begin{array}{c}\text { Coupling } \\
\text { constant } \\
J(\mathrm{~Hz})\end{array}$ & $\begin{array}{c}\text { Carbon } \\
\text { Atom }\end{array}$ & $\begin{array}{c}\delta_{\mathrm{C}} \\
(\mathrm{ppm})\end{array}$ & Proton & $\begin{array}{c}\delta_{\mathrm{H}} \\
(\mathrm{ppm})\end{array}$ & $\begin{array}{l}\text { Integration } \\
\text { peak }\end{array}$ & $\begin{array}{c}\text { Coupling } \\
\text { constant } J \\
(\mathrm{~Hz})\end{array}$ \\
\hline $\mathrm{C}_{2}$ and $\mathrm{C}_{6}$ & 116.6 & $\mathrm{H}_{\mathrm{b}}$ & $6.60(d)$ & 2 & 8.8 & $\begin{array}{c}\mathrm{C}_{3}, \mathrm{C}_{3}, \mathrm{C}_{5} \\
\text { and } \mathrm{C}_{5} \text {, }\end{array}$ & 115.6 & $\mathrm{H}_{\mathrm{b}}$ & 6.74 (d) & 4 & 8.4 \\
\hline $\mathrm{C}_{3}$ and $\mathrm{C}_{5}$ & 129.5 & $\mathrm{H}_{\mathrm{c}}$ & $7.11(\mathrm{~d})$ & 2 & 8.8 & $\begin{array}{c}\mathrm{C}_{2}, \mathrm{C}_{2}, \mathrm{C}_{6} \\
\text { and } \mathrm{C}_{6},{ }^{2}\end{array}$ & 127.4 & $\mathrm{H}_{\mathrm{c}}$ & $7.36(\mathrm{~d})$ & 4 & 8.4 \\
\hline ------- & -------- & $\mathrm{H}_{\mathrm{a}}$ & $3.66(\mathrm{~s})$ & 2 & ---------- & - & --------- & $\mathrm{H}_{\mathrm{a}}$ & $3.67(\mathrm{~s})$ & 4 & ----------- \\
\hline $\mathrm{C}_{1}$ & 145.3 & & & & & $\mathrm{C}_{4}$ and $\mathrm{C}_{4}$ & 146.1 & & & & \\
\hline $\mathrm{C}_{4}$ & 123.6 & & & & & $\mathrm{C}_{1}$ and $\mathrm{C}_{1}$, & 131.9 & & & & \\
\hline
\end{tabular}

The ${ }^{13} \mathrm{C}$-NMR spectrum of $p$-chloroaniline showed four signals assigned to four types carbons (Table 1, Figure 1). In addition, from synthesized compound it is possible to observe four signals corresponding to $\mathrm{C} 4$ and $\mathrm{C} 4$ ' (146.06 ppm); C3, C5, C3', and C5' (115.55 ppm); C2, C6, C2' ,C6' (127.38 ppm), and finally, $\mathrm{C}^{\prime}$ ' and $\mathrm{Cl}^{\prime}$ ' (131.8 ppm). It can be concluded that the synthesized compound corresponds to 4,4'-Biphenyldiamine ${ }^{27}$ (Figure 1).<smiles>Cc1c(C)c(Cl)c(C)c(N(C)C)c1C</smiles><smiles>Cc1c(C)c(N(C)C)c(C)c(C)c1-c1c(C)c(C)c(N(C)C)c(P)c1C</smiles>

Figure 1.Structure of $p$-chloroaniline (1) and 4,4'- biphenyldiamine (2).
In general, laccase uses as substrates phenolic substances rather than aromatic amines ${ }^{28}$. It has been reported than an amine containing two amino groups, $p$-phenylenediamine, can be used as substrate by some laccases ${ }^{29}$. Simmons et al., (1985) demonstrated that when $p$-chloroaniline was incubated with the $T$. versicolor laccase eight products were obtained ${ }^{30}$. These authors proposed that the substrate was enzymatically oxidized and an anilinium free radical was formed, then a free-radical coupling occurred, and three dimeric intermediates were produced through $\mathrm{N}-\mathrm{N}, \mathrm{N}-$ para, and N-ortho radical couplings ${ }^{30}$; however, the compounds structures were not reported. This is the first time that laccase catalyzed synthesis of 4,4'-Biphenyldiamine is reported.

The previously works would indicate that laccase catalyzed dimerization of $p$-chloroaniline would could occur by the radical formation in position para, after amino group oxidation generating a resonance in this position, causing the output of chlorine from the molecule. Supporting this observation, Longoria et al (2008) reported the free-radical generation in position para and ortho of aniline ${ }^{31}$. Based on these experiments, it is possible to conclude that the enzyme, lacasse, is able to produce oxidation in the molecule forming a radical which would give rise formed products. However, the specific mechanism is still unknown.

3.2 Evaluation of antifungal activity of the p-chloroaniline and 4,4'-Biphenyldiamine.

In order to determine the antifungal activity against $B$. cinerea of the compound formed, the effect on mycelial growth at different concentrations was evaluated in a solid medium and the $\mathrm{IC}_{50}$ value of $p$-chloroaniline and 4,4'-Biphenyldiamine were calculated (Table 2). 
Table 2. Effect of $p$-chloroaniline and 4,4'-Biphenyldiamine on the mycelial growth of $B$. cinerea in solid medium.

\begin{tabular}{|c|c|}
\hline Compound & $\mathbf{I C}_{\mathbf{5 0}}(\mathbf{m M})$ \\
\hline $\boldsymbol{p}$-chloroaniline & $1.72 \pm 0.11$ \\
\hline $\mathbf{4 , 4}$ '-Biphenyldiamine & $1.50 \pm 0.19$ \\
\hline Iprodione & 0.0148 \\
\hline
\end{tabular}

4,4'-Biphenyldiamine presented an $\mathrm{IC}_{50}$ value similar to that of p-chloroaniline and both compounds showed a much lower antifungal activity than the commercial fungicide, iprodione ${ }^{32}$.In contrast, it has been described that some dimeric polyphenols are more toxic than monomers. For example resveratrol, a stilbene found in grape, wine and grape pomace show low antifungal activity against $B$. cinerea $^{33,34}$. However, a specific laccase of this fungus converted resveratrol into a more fungitoxic dimer that caused it selfintoxication ${ }^{35}$. Thus, the utilization of the homomolecular dimeric compound to inhibit the hyphal growth of $B$. cinerea will be limited.

3.3 Evaluation of antioxidant activity from p-chloroaniline and 4,4'-Biphenyldiamine.

The antioxidant activity from both compounds using a ORAC-PGR method was performed. The Figure 2 shows the PGR oxidation and the antioxidant effect of 4,4'-Biphenyldiamine and $p$-chloroaniline. This result suggests that the antioxidant capacity of $p$-choloaniline was slightly increased by the dimerization. A possible explanation to this phenomenon is that in 4,4'-Biphenyldiamine structure there are two linked-phenyl groups in position para in relation to amine group producing a greater stability of radicals. However, the antioxidant ability of 4,4'-Biphenyldiamine was lesser than the antioxidant Trolox

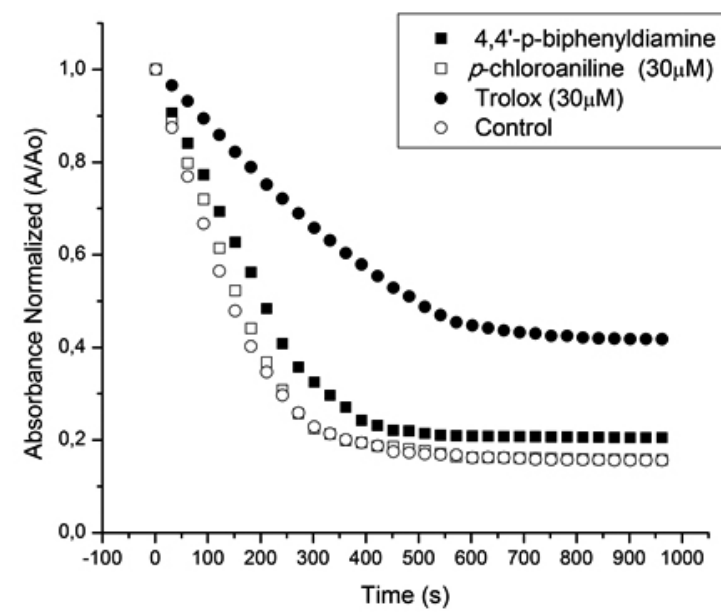

Figure 2. Antioxidant activity of $p$-chloroaniline and 4,4'-Biphenyldiamine obtained by ORAC-PGR method.

\section{CONCLUSIONS}

In conclusion, it was shown that $p$-chloroaniline can be used as substrate by the $T$. versicolor lacasse and 4,4'-Biphenyldiamine was obtained as product by a coupling reaction. The synthesis of this compound in a lacasse catalyzed reaction has not been reported previously. This compound presented a low antifungal activity; however, the antioxidant ability was slightly increased by the dimerization of $p$-chloroaniline.

\section{ACKNOWLEDGEMENTS}

The authors thank to DICYT Grant from Universidad de Santiago de Chile and Fondecyt 1130389 for the financial support.

\section{REFERENCES}

1. O.V. Morozova, G.P. Shumakovich, M.A. Gorbacheva, S.V. Shleev, A. Yaropolov, Biochem.72, 1136, (2007).

2. T. Kudanga, G.S. Nyanhongo, G.M. Guebitz, S. Burton, Enz. Microbial
Tech. 48, 195, (2011).

3. U. Jonas, E. Hammer, E.T.K. Haupt, F. Schauer, Arch. Microbiol.174,393 (2000).

4. T. Shiba, L. Xiao, T. Miyakoshi, C. Chen, J. Mol. Catal. B. Enzym, 10(6), 7 (2000).

5. O.E. Adelakun,T. Kudanga,A. Parker,I.R. Green, M. le Roes-Hill, S.G Burton,. J. Mol. Catal. B Enzym.74, 29, (2012).

6. S. Witayakran,A.J. Ragauskas, Adv. Synth. Catal.351, 1187, (2009).

7. T.H.J. Niedermeyer, A. Mikolasch, M. Lalk, J. Org. Chem.70, 2002 (2005).

8. V. Ibrahim, N. Volkova,S.H. Pyo, G. Mamo, R. Hatti-Kaul, Acid. J. Mol. Catal. B Enzym.97, 45, (2013).

9. A. Mikolasch, T.H.J. Niedermeyer, M. Lalk, S. Witt, S. Seefeldt, E. Hammer, F. Schauer, M. Gesell, S. Hessel, W.D. Jülich, et al. Chem. Pharm. Bull. (Tokyo).54, 632, (2006).

10. A. Mikolasch, S. Hessel, M.G. Salazar, H. Neumann, K. Manda, D. Gordes, E. Schmidt, K. Thurow, E. Hammer, U. Lindequist, et al. Chem. Pharm. Bull.56, 781, (2008).

11. A. Mikolasch, T.H.J. Niedermeyer, M. Lalk, S. Witt, S. Seefeldt, E. Hammer, F. Schauer, M. Gesell Salazar, S. Hessel, W.D. Jülich, et al. Chem. Pharm. Bull. (Tokyo).55, 412, (2007)

12. K.W. Wellington, N.I. Kolesnikova, Bioorg. Med. Chem.20, 4472, (2012).

13. J.R. Jeon, Y.S. Chang, Trends in Biotechnology, 31(6), 335, (2013).

14. G. Shumakovich, V. Kurova, I. Vasil'eva, D. Pankratov, G. Otrokhov, O. Morozova, A. Yaropolov, J. Mol. Catal. B. Enzym. 77,105, (2012).

15. M. Kurisawa, J. Chung, H. Uyama, S. Kobayashi, Biomacromolecules, 4, 1394 (2003).

16. M.G. Hossain, M.D. González, G.R. Lozano, T. Tzanov, J. Biotech. 141, 58 (2009).

17. A.A.Leontievsky, N.M. Myasoedova, B.P. Baskonov, L.A. Golovleva, C.S. Evans. Biodegradation 11(5), 331, (2000).

18. G. Dawel, M. Kastner, J. Michels, W. Poppitz, W. Gunther, W. Fritsche, Applied Environ. Microbiol. 63(7), 2560, (1997).

19. J. F. Osma, J. Toca-Herrera, S. Rodriguez-Couto, Dyes \& Pigments, 75, $32,(2007)$.

20. C. Cantarelli, Vinid'Italia, 3, 87, (1986).

21. M. Božiča, J. Štrancarb, V. Kokola, Reac. Func. Polymers 73(10), 1377, (2013).

22. A. Aljawish, I. Chevalot J. Jasniewski, A.M. Revol-Junelles, J. Scher, J. Muniglia, Food Chem. 161, 279, (2014).

23. P. Leroux in the Chemical Control of Botrytis and Its Resistance to Chemical Fungicides. In Botrytis: Biology, pathology and control; Y. Elad, B. Williamson, P. Tudzynski, N. Delen, N., Eds.; Springer: Dordrecht, Netherlands, 2007; pp. 195-217.

24. G. Muñoz, P. Hinrichsen,Y. Brygoo, T. Giraud, Mycol. Res.106, 594, (2002).

25. A.C. Poblete, B. E. López-Alarcón, C. Lissi, A.M. Campos, J. Chil. Chem. Soc. 54(2), 14, (2009).

26. R. Silverstein, F. Webster, D. Kiemle. Spectrometric identification of organic compounds, John Wiley \& Sons, (2005)

27. D. Hinks, H.S. Freemana, M. Nakpathoma, J. Sokolowskab, (2000). Dyes and Pigments, 44(3), 199, (2000).

28. T. Hoff, S.Y. Liu, J.M. Bollag, App. Environ. Microbiol. 49 (5), 1044 , (1985).

29. W.G. Levine, W. G. in the Laccase, a review, In J.J. Peisach, D. Aisen, and W.E. Blumberg, ed. The biochemistry of copper. Academic Press, Inc., New York, (1966); p. 371-387

30. K.E. Simmonds, R.D. Minard, J.M. Bollag, Environ. Sci. Technol. 27, 999, (1987)

31. A. Longoria, H. Hub, R. Tinoco-Valencia, R. Vásquez-Duhalt, TIP Revista Especializada en Ciencias Químico-Biológicas, 11(2), 73, (2008).

32. L. Mendoza, M. Cotoras, M. Vivanco, B. Matsuhiro, S. Torres, M.J. Aguirre, J. Chil. Chem. Soc. 58(2), 1725, (2013).

33. M. Adrian, P. Jeandet, J. Veneau, L. Weston, R. Besis, J. Chem. Ecol. 23 $1689,(1997)$.

34. F. Caruso, L. Mendoza, P. Castro, M. Cotoras, M.J. Aguirre, B. Matsuhiro, M. Isaacs, M. Rossi, A. Viglianti, R. Antonieletti,. PLOS-ONE 6(10), e25421, (2011)

35. A.Schouten, L. Wagemakers, F.L. Stefanato, R.M. Van der Kaaij, J.A.L van Kan, Mol. Microbiol. 43, 883, (2002). 